\title{
IMPACTOS AMBIENTAIS DECORRENTES DA CONSTRUÇÃO DA USINA HIDRELÉTRICA DE BATALHA NO RIO SÃO MARCOS: APREENSÃO POR PARTE DOS MORADORES DO ENTORNO DAS OBRAS ENVIRONMENTAL IMPACTS OF THE BATALHA HYDROPOWER CONSTRUCTION IN SAO MARCOS RIVER: SEIZURE OF PART THE DWELLERS IN SURROUNDING WORK
}

\begin{abstract}
Aline de Arvelos Salgado
Doutoranda do Programa de Pós-Graduação em Ciências Ambientais pela Universidade Federal de Goiás (UFG).
\end{abstract}

\section{Agustina Rosa Echeverría}

Doutora em Educação, docente da Universidade Federal de Goiás (UFG), atuando no Instituto de Química, no Programa de Pós- Graduação em Educação em Ciências e Matemática e no Programa de Pós-Graduação em Ciências Ambientais dessa universidade.

\section{Fernanda Posch Rios}

Doutora em Ciências Ambientais, docente do Instituto Federal de Educação, Ciência e Tecnologia de Goiás (IFG-GO).

\section{Patrícia Layne Alves Traldi}

Doutora em Ciências Ambientais, docente do Instituto Federal de Educação, Ciência e Tecnologia de Goiás (IFG-GO).

\section{Marta Pereira da Luz}

Engenheira civil, doutora em Ciências Ambientais, Engenheira da Eletrobras Furnas e docente da Pontifícia Universidade Católica de Goiás (PUC-GO).

\section{Endereço para correspondência:}

Aline de Arvelos Salgado - Avenida Universitária, Quadra 86, Lote Área, 1488 - Setor Leste Universitário CEP 74605-220-Escola de Engenharia Civil e Ambiental Goiânia (GO), Brasil -E-mail: alinearvelos@hotmail.com

Recebido: 21/01/2016

Aceito: 12/06/2017

\section{RESUMO}

Esta pesquisa objetivou analisar a concepção ambiental dos atores sociais envolvidos na implantação da usina hidrelétrica (UHE) de Batalha, localizada no Rio São Marcos, nos municípios de Cristalina (GO) e Paracatu (MG), por meio da realização de entrevistas semiestruturadas com 18 moradores. Para os entrevistados, o ambiente é visto como natureza, recurso e lugar para se viver. Os problemas ambientais na região estão, em sua maioria, relacionados à instalação da usina e, também, em alguns casos, vinculados às práticas antrópicas cotidianas. Em relação ao entendimento das ações promovidas pela empresa Eletrobras Furnas durante a instalação do empreendimento, este se configura de forma diferente de acordo com o grupo de moradores. Quanto à implantação da usina, identificam-se pontos positivos (necessidade de demanda energética, recebimento de casas novas, indenizações, apoio técnico e cursos providos por Furnas) e negativos (desterritorialização, perdas sociais, financeiras, descontentamento com algumas ações de Furnas e impactos ambientais). Como resultado, verificou-se a necessidade de promover maior participação das pessoas na tomada de decisões, bem como criar meios de comunicação mais formais que possam, de fato, sanar as dúvidas em relação às questões e aos impactos socioambientais na região, decorrentes da implantação desse tipo de empreendimento.

Palavras-chave: entrevistas semiestruturadas; ambiente; educação ambiental; Goiás; Minas Gerais.

\section{ABSTRACT}

This research aimed to analyze the environmental conception of the social actors involved in the implementation of the Batalha HPP, located in the São Marcos River, in the municipalities of Cristalina (GO) and Paracatu (MG), through semi-structured interviews with eighteen residents. For those interviewed the environment is seen as nature, resource and place to live. The environmental problems in the region are mostly related to the installation of the hydropower and also mention some linked to their daily anthropic practices. Regarding understanding the actions promoted by Furnas company during the installation of the hydropower, this configuration is different according to the group of residents. Regarding the implantation of the hydropower, they identify strengths (need for energy demand, reception of new houses, indemnities, technical support and courses provided by Furnas) and weaknesses (deterritorialization, social losses, financial dissatisfaction with some Furnas actions and environmental impacts). As a result, there was the need to promote greater participation of people in decision making, as well as to create more formal media that can actually solve any doubts on the issues and environmental impacts in the region, resulting from the implementation of this type entrepise.

Keywords: semistructured interviews; environment; environmental education; Goiás; Minas Gerais. 


\section{INTRODUÇÃO}

Os problemas ambientais ocorridos na década de 1960 representaram uma crise na civilização: um questionamento sobre a progressão da modernidade e as perspectivas de visões de sustentabilidade, que fez com que a fusão da natureza e da cultura ficasse dividida pelo dualismo ontológico e epistemológico dos tempos atuais. Assim, o movimento ecológico surgiu, com outras questões sociais, e apresentou a crise ambiental decorrente do desenvolvimento econômico e tecnológico. Com a crise ambiental, a natureza passou a estar envolvida no debate epistemológico e político sobre a sustentabilidade da vida. Com o capitalismo, foi abandonado o princípio que afirmava que a natureza era apenas a fonte da riqueza natural. O processo econômico tornou-se um crescente processo de produção, mobilizado por combustíveis fósseis que lentamente, porém de modo irreversível, transformou-se em degradação ambiental e ecológica do planeta (PORTO-GONÇALVES \& LEFF, 2015).

Segundo Porto-Gonçalves (2016), a humanidade e o Planeta estão passando por um período de metamorfose, que provoca um questionamento sobre uma nova era geológica - "Antropoceno" ou "Capitaloceno" -, na qual o homem seria o principal responsável pelos impactos ocorridos.

Com o crescimento acelerado da população, cada vez mais há a necessidade de se utilizar os recursos naturais, de modo que possam ser atendidas as demandas decorrentes do aumento populacional. Pode-se citar como exemplo os reservatórios de água que vêm sendo construídos para atender aos múltiplos usos, como irrigação, geração de energia, pesca, controle de cheias, abastecimento público, entre outros.

A construção de usinas hidrelétricas (UHEs) causa transformações que afetam tanto o ambiente quanto as populações humanas e demais biotas, que são atingidas pela construção dos reservatórios. A implantação desse tipo de empreendimento provoca impactos ambientais e sociais, que modificam a região e a vida das pessoas que estão próximas à área da construção, o que justifica investigar tanto os impactos socioambientais quanto a compreensão dos indivíduos a seu respeito.

Porto-Gonçalves e Leff (2015) realizaram uma pesquisa sobre ecologia política na América Latina. Para os autores, trata-se de um campo disciplinar e político da fusão de diferentes racionalidades na apropriação social da natureza e para a construção de um futuro sustentável, que demanda a desconstrução de teorias e práticas instituídas e enraizadas na maior parte da vida das pessoas, para estabelecer novas relações socioambientais. Um dos pontos fortemente debatidos na ecologia política dos movimentos socioambientais latino-americanos é a definição de novos caminhos para se construir um ambiente mais sustentável com base em suas características culturais e seus potenciais ecológicos.

A presente pesquisa buscou compreender os impactos socioambientais ocasionados por construções de hidrelétricas a partir dos princípios da Educação Ambiental, que prioriza a análise das relações políticas, econômicas, sociais e culturais entre a humanidade e a natureza, bem como as interações entre os seres humanos, como meio de superação dos mecanismos de controle e dominação que impedem a participação livre, consciente e democrática de todos (REIGOTA, 2009). Para tanto, objetivou-se analisar a concepção ambiental de pessoas envolvidas na implantação de uma UHE situada nos municípios de Cristalina (GO) e Paracatu (MG), como forma de avaliar o conhecimento, a compreensão e a reflexão desses sujeitos.

A pesquisa ocorreu em assentamentos situados na Área de Influência Direta (AID) da UHE de Batalha. Segundo IBASE e FURNAS (2010), tais assentamentos foram criados sob amparo da Lei $n^{0} 4.504 / 1964$ (BRASIL, 1964), que regula os direitos e as obrigações concernentes aos bens imóveis rurais para fins de execução da reforma agrária. Nessa área, já existiam cinco projetos de assentamentos rurais, sendo quatro no município de Cristalina (Vista Alegre, Buriti das Gamelas, São Marcos e Casa Branca) e um no município de Paracatu (Jambeiro).

Todos os assentamentos da AID da UHE de Batalha foram criados entre 1999 e 2000, a partir da ocupação de propriedades por trabalhadores rurais sem-terra. As áreas originais foram desapropriadas e ocorreu a distribuição de lotes, a partir de planos de assentamento desenvolvidos pelo Instituto Nacional de Colonização e Reforma Agrária (INCRA). Em 2010, foi criado um sexto assentamento, denominado São Cristóvão, para 
receber algumas das famílias que tiveram seus lotes parcial ou totalmente atingidos durante a primeira implantação da UHE de Batalha (IBASE; FURNAS, 2010).

A pesquisa ocorreu em assentamentos situados na Área de Influência Direta (AID) da UHE de Batalha (Figura 1).

A ocupação do Projeto de Assentamento (PA) Jambeiro iniciou-se na fazenda de mesmo nome em 1998 e seu processo de implantação durou até 2001. Esse assentamento está situado em Paracatu (MG), a aproximadamente $80 \mathrm{~km}$ da cidade, sendo o maior da AID da UHE de Batalha, com 26 lotes parcialmente afetados por sua construção. Tem $10.898,861$ ha e está dividido em 195 parcelas, o que corresponde ao mesmo número de famílias. A média das áreas dos lotes, nesse assentamento, é de 40 ha. Nele, há seis áreas de Reserva Legal e quatro áreas comunitárias, entre elas, a Escola Municipal Pedro Silva Neiva (IBASE; FURNAS, 2010). O PA Jambeiro abrigou famílias do interior de Minas Gerais e Goiás, originalmente integrantes do grupo de sem-terra coordenados pelo Sindicato dos Trabalhadores Rurais (STR) de Paracatu e de Guarda-Mor e pela Federação dos TrabaIhadores da Agricultura do Estado de Minas Gerais
(FETAEMG). A pesquisa ocorreu em assentamentos situados na Área de Influência Direta (AID) da UHE de Batalha (Figura 1).

O acesso à educação para essas famílias é garantido pela presença de escolas no assentamento rural e no interior de algumas propriedades, sendo que o ensino médio permanece restrito à área urbana de Cristalina e Paracatu. $O$ transporte escolar é de responsabilidade das prefeituras municipais. No PA Jambeiro não existem postos de saúde, sendo todo o atendimento realizado nas cidades ou por meio de visitas periódicas de uma equipe médica que atende à população nas escolas locais. $O$ assentamento também conta com associação de moradores formalizada.

Na implantação da UHE de Batalha, parte dos terrenos do PA Jambeiro foi inundada, fazendo com que 14 das famílias ali residentes fossem transferidas para o PA São Cristóvão. É importante mencionar que este último assentamento foi constituído por meio da aquisição de uma área de 700 ha na zona rural do município de Paracatu pela empresa Furnas Centrais Elétricas e formalmente doada ao INCRA em setembro 2010 (IBASE; FURNAS, 2010).

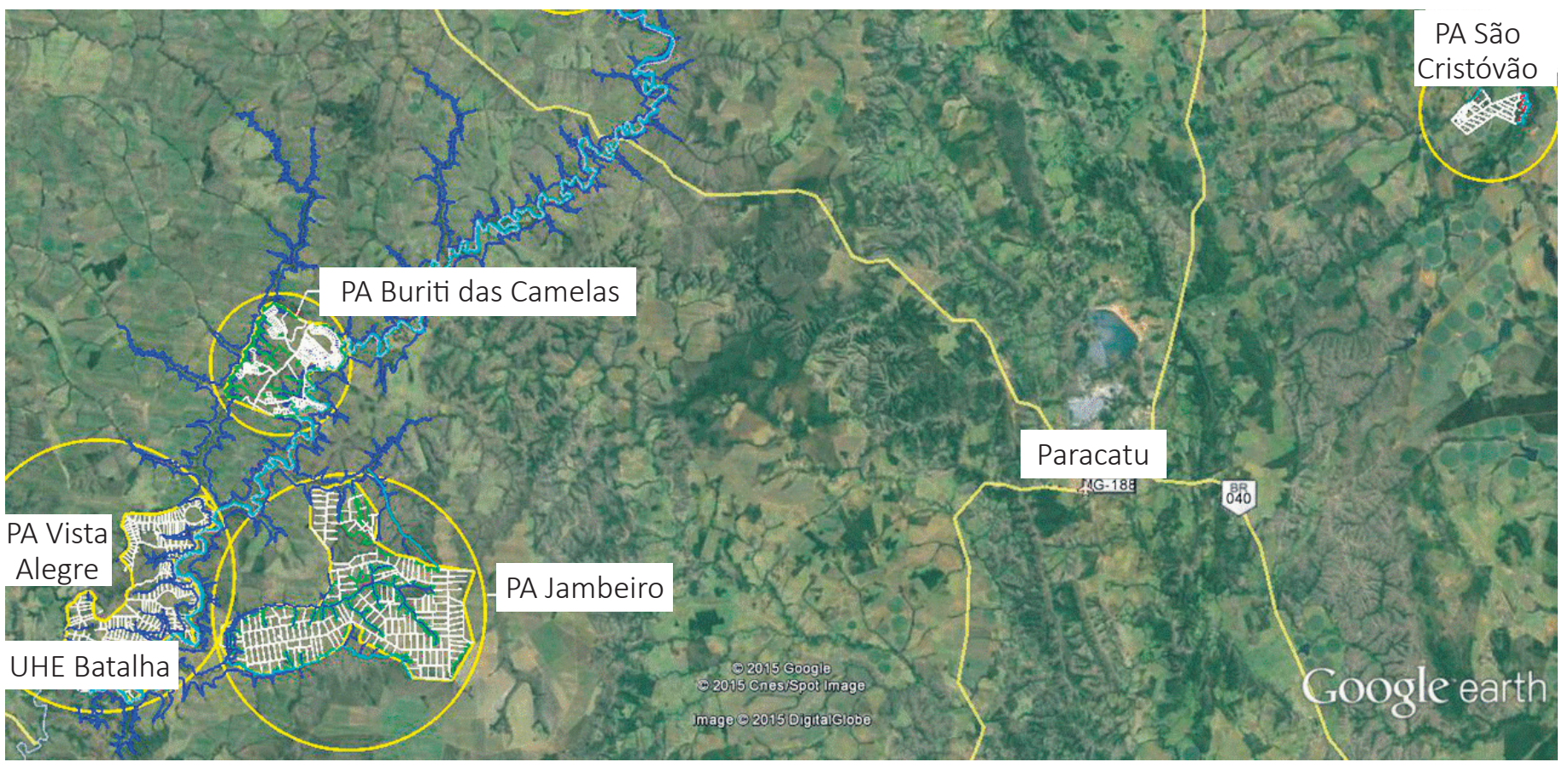

Fonte: Google Earth, 2015.

Figura 1 - Mapa de localização dos assentamentos. 


\section{CARACTERIZAÇÃO METODOLÓGICA DA INVESTIGAÇÃO}

A pesquisa caracterizou-se metodologicamente como qualitativa empírica (BOGDAN; BIKLEN, 1994), utilizando entrevistas semiestruturadas e diário de campo.

Para a realização das entrevistas, foram selecionadas 18 famílias residentes na AID de Batalha, mais especificamente nos assentamentos Jambeiro e São Cristóvão. As entrevistas foram orientadas por um roteiro com perguntas principais, complementadas por outros pontos inerentes às circunstâncias momentâneas do diálogo, de modo a garantir o foco sobre o assunto. As questões formuladas tiveram o objetivo de conhecer os fenômenos (conhecimento, compreensão e reflexão) dos sujeitos sobre a concepção ambiental. O projeto de investigação, a metodologia e o roteiro foram previamente aprovados pelo Comitê de Ética em Pesquisa da Universidade Federal de Goiás (UFG).

Para a interpretação das transcrições dos entrevistados, aqui identificados como E1 a E18, foi aplicada a técnica de análise de conteúdo temático-categorial de Bardin (2011), utilizada por Cassiano \& Echeverría (2014) e Rios (2015), que favorece a compreensão da construção de significados que os atores sociais exteriorizaram durante a entrevista, de modo a atingir níveis de compreensão mais detalhados do fenômeno. De acordo com tal proposta, a preparação do material para análise iniciou-se com a transcrição integral das entrevistas e a realização de leituras flutuantes com objetivo exploratório. Em seguida, foi efetuada a operação de pré-análise, com a formulação de hipóteses e objetivos e a elaboração de índices que fundamentaram a interpretação final, com o alinhamento dos enunciados intactos, de maneira a permitir uma classificação por equivalência. Foi realizada a inferência com base na presença do índice (tema, palavra, entre outras), e não sobre a frequência da sua aparição.

Como ferramenta de auxílio à análise de dados oriundos de pesquisas qualitativas, como a aqui abordada, foi utilizado o software WebQDA (Web Qualitative Data Analysis) para estruturação e simplificação do processo de categorização, potencializando a síntese dos resultados e trazendo a transparência e o rigor técnico necessários a toda pesquisa científica (LOPES et al., 2013).

\section{INTERPRETAÇÃO DOS RESULTADOS}

A implantação da UHE de Batalha afetou de forma distinta a vida dos moradores da região de sua AID. Assim, foram identificados grupos de acordo com suas características em relação à maneira como as pessoas foram afetadas pela implantação da usina (Figura 2). As características são:
1. Indiretamente atingidos: entrevistados residentes no PA Jambeiro, cujas terras não foram diretamente inundadas com a construção do reservatório da UHE de Batalha.

2. Atingidos: entrevistados que moram no PA Jambeiro, os quais tiveram suas terras diretamente

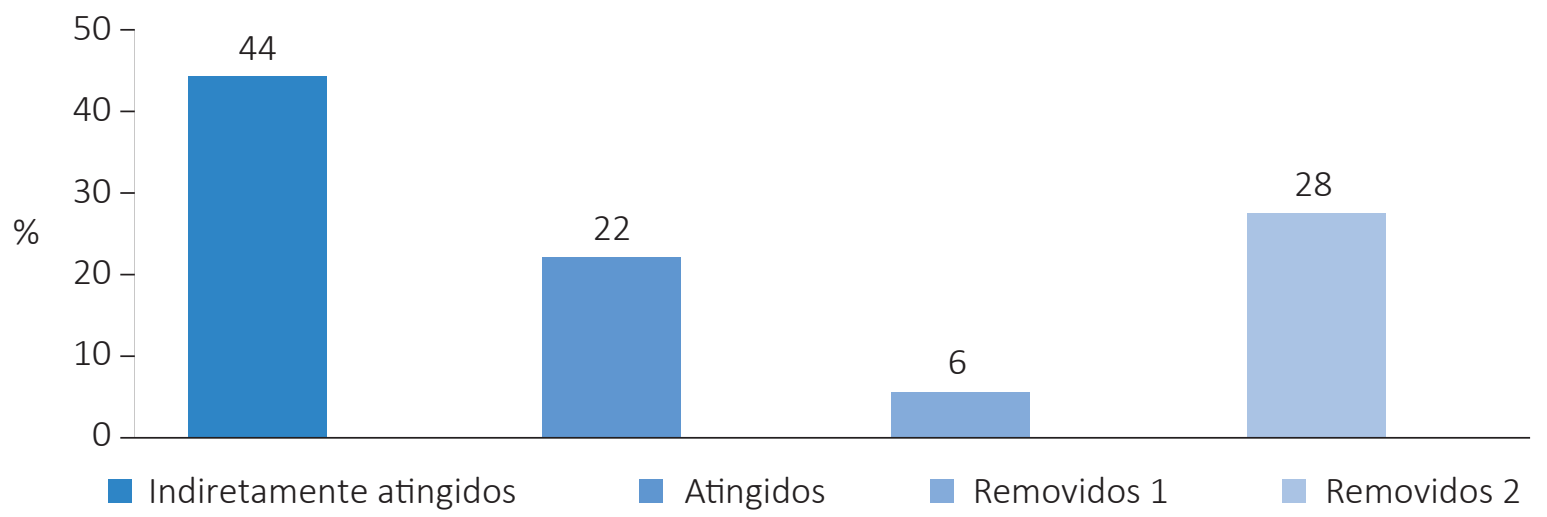

Figura 2 - Distribuição dos grupos de entrevistados de acordo com o grau de impacto da implantação da Usina Hidrelétrica de Batalha. 
inundadas com a construção do reservatório da UHE de Batalha.

3. Removidos 1: entrevistados residentes no PA Jambeiro que, em virtude de suas terras terem sido totalmente afetadas com a construção da UHE de Batalha, foram transferidos de propriedade dentro do mesmo assentamento (PA Jambeiro).

4. Removidos 2: entrevistados que passaram a residir no PA São Cristóvão em virtude de suas terras localizadas no PA Jambeiro terem sido direta e/ou totalmente afetadas com a construção da UHE de Batalha.

A partir da análise de conteúdo temático-categorial das entrevistas, pode-se delimitar quatro categorias que expressam as ideias comuns entre os moradores diante de suas realidades individuais após a instalação da UHE de Batalha. Essas categorias têm seus respectivos

\section{Categoria 1 - Concepções de ambiente}

A categoria "Concepções de ambiente" está relacionada à maneira que os indivíduos entrevistados percebem o ambiente e às possíveis intervenções dele em suas vidas cotidianas. Ao analisar as assertivas dos entrevistados, buscou-se identificar trechos que representassem os principais conceitos de ambiente, revelando a existência ou não do sentimento de pertencimento a ele. significados expressos no Quadro 1, cujos conteúdos abordados foram:

1. Concepções de ambiente - análises das seguintes compreensões acerca de: natureza; recurso; e lugar para se viver.

2. Responsabilidade perante o ambiente - identificação como "agente responsável" enquanto indivíduo, comunidade e empresa Furnas.

3. Implicações ambientais da implantação da UHE de Batalha - alterações físicas, emocionais, sociais e financeiras no universo individual/familiar.

4. A interpretação da população local acerca das ações promovidas pela empresa Furnas vinculadas à UHE de Batalha - apreensão da comunidade quanto às ações mitigadoras implementadas pela empresa na comunidade afetada.

Sauvé (2005) aponta que há diferentes concepções de ambiente. Existe a compreensão do ambiente enquanto natureza, que é remetido à apreciação, ao respeito e que deve ser preservado; ambiente visto como recurso, o qual deve ser gerido ou repartido, o que explicita o entendimento da impossibilidade da existência da vida sem os recursos naturais; ambiente visto como um problema, com relação à prevenção ou na resolução dos

Quadro 1 - Categorias identificadas por meio das entrevistas com moradores da Área de Influência Direta da Usina Hidrelétrica de Batalha e seus significados.

Categorias

1. Concepções de ambiente

2. Responsabilidade perante o ambiente

3. Implicações ambientais da implantação da UHE de Batalha

4. A interpretação da população local das ações promovidas pela empresa Furnas vinculadas à UHE de Batalha

\section{Significados}

Reconhecimento dos principais conceitos de ambiente, revelando a existência ou não do sentimento de pertencimento ao ambiente.

Identificação na fala dos entrevistados de noções de responsabilidade quanto aos cuidados com o ambiente, bem como seus impactos, por parte individual, coletiva e da empresa Furnas.

Compreensão das principais modificações causadas pela implantação da UHE de Batalha na vida cotidiana dos moradores, com discernimento dos impactos ambientais oriundos do empreendimento ou provenientes de costumes locais.

Identificação das opiniões em relação às ações promovidas pela empresa Furnas, durante todo o processo de implantação da UHE de Batalha. 
impactos que são causados a esse; ambiente entendido como sistema, que inclui toda a riqueza, diversidade e complexidade do seu meio, que define seu próprio "nicho" dentro do sistema global; ambiente como o lugar em que se vive no cotidiano; ambiente biosfera, para se viver junto e em longo prazo; e o ambiente enquanto projeto comunitário, que é o espaço para que todos colaborem efetivamente para que aconteçam as mudanças desejadas pela comunidade.

Entre os significados de ambiente apontados por Sauvé (2005), identificam-se nos indivíduos entrevistados visões sob o ponto de vista da natureza, recurso e lugar para se viver.

Entre as falas dos entrevistados, podem-se destacar:

- Visão de natureza: ambiente enquanto natureza, compreendido como lugar para apreciar, respeitar e preservar.

E1: O ambiente, eu suponho, que é um meio da vida em geral. Tanto flora quanto fauna, tudo. Ele é sempre importante, tanto para mim, quanto para todos.

E5: O ambiente [...] eu acho que é tudo a nossa volta, a natureza, tudo.

E6: O ambiente é um todo que está ao nosso redor. Envolve o todo, animal, planta, água, ar.

E10: O ambiente para mim é tudo o que está a nossa volta. É a natureza, os rios.

E11: O ambiente é isso aqui, natural assim. As árvores, os bichos, os passarinhos.

E12: É uma beirada de córrego, as árvores mesmo.

- Visão de recurso: ambiente visto como recurso para gerir, repartir.

E11: O ambiente é importante para quem mora na cidade também [...], se não tivermos ele aqui como vão comer na cidade?

E14: A natureza é uma aliada [...] você pode desfrutar sem derrubar [...]

- Visão de lugar para se viver: ambiente como local para se viver, morar.

E3: O ambiente é tudo que nos envolve. Plantas, árvores, a escola, a comunidade, tudo. Nós estamos ligados à Terra em tudo.

E4: O ambiente é o mundo que estamos inseridos. É tudo. São as pessoas, os animais, as plantas.

E8: O ambiente é o lugar que a gente convive.

E9: $O$ ambiente é isso aqui tudo que a gente vive. É o planeta, o mundo, a terra, a coisas, as pessoas que estão aqui. Tudo aqui para mim é o ambiente.
Observou-se que, quando questionados sobre o ambiente, os entrevistados apresentaram a predominância de relacioná-lo a ideias que remetem a "natureza", "vida biológica", "flora e fauna". Esse olhar "naturalizado" enxerga a natureza como mundo da ordem biológica, essencialmente boa, que se encontra pacificada, estável, equilibrada nas relações ecossistêmicas, a qual se estabelece como autônoma e independente da interação com o mundo cultural humano e que, quando ocorre esse encontro, a presença antrópica é vista como problemática e nefasta para a natureza (CARVALHO, 2006). Esse fato é notado nas falas de alguns entrevistados, quando dizem que a construção da usina causou impactos, que começaram a aparecer alguns problemas ambientais que antes não existiam.

\footnotetext{
E9: Para a construção da usina, alagou uma área muito grande e algumas árvores foram retiradas. Poderia ter acontecido sem essa inundação. Aí desalojou os bichos que estavam lá, e eles vão procurar outro lugar para morar, perto da nossa casa.
}

Para Porto-Gonçalves (2004), a natureza, em nossa sociedade, é compreendida por aquilo que se opõe à cultura. Esta é tomada como algo superior e que conseguiu controlar e dominar a natureza. Já a natureza é vista como um objeto de dominação pelo homem; e a expressão "dominar a natureza" só tem sentido a partir da premissa de que o homem não é natureza.

Guimarães (2005) aponta que as pessoas adquirem cada vez mais a postura de não serem parte integrante da natureza como um todo, o que as faz ficar distante dela, levando o homem a não perceber as relações de harmonia e desequilíbrio existentes na natureza.

Segundo Grün (2005), esse distanciamento entre sujeito e natureza é resultado do Antropocentrismo, que coloca o homem como o centro de tudo, de modo que a natureza existe apenas como um objeto em função dos humanos - as pessoas seriam "senhores e possuidores da natureza". O autor cita ainda que esse não pertencimento à natureza, refletido na objetivação e fragmentação desta, é resultado da busca da autonomia da razão e isso pode ser considerado um dos elementos responsáveis pela devastação ambiental, em razão da separação entre sujeito e objeto e natureza e cultura. Para solucionar essa crise ecológica, é necessária uma postura holística, que não seja reducionista 
e fragmentada, que almeje integrar os seres humanos à natureza.

A crise ambiental dos tempos atuais é o resultado de uma crise societária de grande magnitude, que em nenhuma outra época foi observada justamente por ser intrínseca ao movimento de expansão capitalista, de relações sociais alienadas e de redução da vida ao status de mercadoria (LOUREIRO, 2015).

Porto-Gonçalves (2016) cita que é tempo de uma crise epistemológica e política, que encontra uma separação entre sociedade e natureza. A questão de a Terra ser vista "apenas" como um planeta somente será su- perada quando ela não for mais compreendida como uma abstração, e sim como algo que sente e pulsa por meio de diferentes geografias, culturas, regiões, cursos de água que fazem conexões com a terra e a Terra em seus caminhos.

Sauvé (2005) afirma que o ambiente é o cadinho em que se forjam nossa identidade, nossas relações com os outros, nosso "ser no mundo", e ressalta que, por meio do reconhecimento de pertencimento à natureza, pode-se definir a si mesmo e o próprio grupo social, respeitando as relações mantidas com o lugar em que se vive.

\section{Categoria 2 - Responsabilidade perante o ambiente}

"Responsabilidade perante o ambiente" constitui uma categoria configurada a partir dos pontos de vista dos entrevistados no que tange às ações de cuidado, preservação e conservação do ambiente. As subcategorias referem-se à identificação das atribuições do dever e da obrigação por parte individual, coletiva, da empresa Furnas e do governo em assumir tais responsabilidades diante dos impactos ambientais.

Nas falas dos atores sociais pesquisados, destacaramse as seguintes afirmações:

- Responsabilidade individual

E2: Eu acho que quem tem que cuidar do ambiente são as pessoas é de quem mora no assentamento. Porque quando ele ganhou a terra, ele ganhou 40 hectares para ele usufruir e 8 para ele preservar.

E6: A responsabilidade relativa aos cuidados do ambiente é de cada ser. Cada pessoa está no mundo, aí é obrigação dele, eu faço uma parte, você outra, outro a outra, e aí vai. Não tem um responsável específico e único. Se eu for esperar, por exemplo, uma área governamental só para ela cuidar, ela não vai dar conta. É o caso da dengue em Paracatu.

- Responsabilidade coletiva

E1: Eu acho que essa questão de ambiente tem que ser em conjunto, todos juntos, todo mundo, caso contrário, não adianta.

E3: Furnas veio e fez o serviço dela. Mas agora a comunidade que vai tomar conta do ambiente, das coisas que estão ao redor. Se precisar de verba, aí o governo é o responsável. Mas, no total, em geral, quem tem de cuidar são os que estão vivendo aqui e precisam disso daqui para sobreviver.
E5: Todo mundo é responsável pelo ambiente. População, governo, governantes, entidades, todos.

- Responsabilidade de Furnas

E15: A responsabilidade é da comunidade. Mas acho que Furnas tem que cuidar mais. Acho que ela está cuidando pouco.

E17: A responsabilidade é de Furnas e mais as comunidades. Porque a Furnas é maior, porque o impacto dela foi muito maior que o da população. Igual boa parte da responsabilidade é dela. Agora o resto, as pessoas que vivem em torno da barragem estão para isso. Todo mundo.

Para os entrevistados, é notório o reconhecimento do ambiente como um bem comum, e as funções de cuidar, preservar e conservar este bem são atribuídas a todos que se inserem nesse meio. Também é possível observar nas falas a visão de que a empresa Furnas tem responsabilidades em relação ao ambiente, em função dos impactos decorrentes da instalação da usina. Entretanto, existe a recorrência da importância das atitudes individuais e da identificação da necessidade da prática de todos para que haja consolidação das referidas funções citadas. Essa perspectiva integra a concepção ambiental conservadora que, segundo Guimarães (2004b), é uma visão de mundo que fragmenta a realidade, que simplifica, reduz e, assim, perde a riqueza e a diversidade da relação, que é complexa e está além da soma das partes como totalidade. Não compreende que essa relação se dá no processo e não, simplesmente, no sucesso da mudança comportamental de um indivíduo. 
As pessoas tendem a associar as causas dos problemas ambientais a um desvio comportamental, seja do indivíduo, seja do sistema social. Assim, a solução para tal questão se traduz em um apontamento do erro e na garantia do comportamento correto individual, que assim traria uma perspectiva de que, no somatório de indivíduos com atitudes ecologicamente corretas, surgiria a solução do problema (GUIMARÃES, 2011). Como Guimarães (2005), entendemos que a noção de totalidade é fundamental para a compreensão e para a ação equilibrada no ambiente, que é inteiro e não fragmentado.

O meio ambiente é definido na Constituição Federal (BRASIL, 1988) como "bem comum", de uso do povo e essencial à qualidade de vida. $O$ dever de defesa e preservação é atribuído tanto ao Poder Público quanto à coletividade.

Pardo (2008) ressalta que as riquezas que fazem parte da Terra não são recursos naturais, mas bens comuns, dos quais ninguém pode se apropriar, a partir do momento que esse recurso natural também é dos outros. $\mathrm{O}$ autor cita ainda que bens comuns fazem parte de um único ecossistema, que será irreparavelmente modificado se for recorrido de maneira possessiva, refletido por uma falsa propriedade. Os bens comuns não estão à venda e não são negociáveis justamente por serem comuns; também não são bens públicos ou bens naturais. Os bens comuns estão além dos bens particulares e estão integrados ao ecossistema como uma biorregião dentro de uma grande esfera em que todos estão interligados.

Loureiro (2012) alerta que apenas instrumentos jurídicos não são suficientes para a garantia do ambiente capaz de atender às necessidades públicas e individuais. Os entrevistados demonstraram uma visão ingênua de que a responsabilidade de suas ações individuais, replicadas pelo coletivo, já seriam suficientes para a preservação, pois o pressuposto de ambiente, enquanto um bem comum, definido por lei, exige a garantia de justiça para o acesso à riqueza e, consequentemente, aos bens naturais. Porém, esses anseios são dificilmen- te alcançáveis em uma sociedade capitalista, em que há uma desigualdade de condições de vida, as quais produzem um mundo desigual.

Silva (2009) apresenta que a relação entre ambiente e educação é reducionista, estando associado a ações imediatistas, que muitas das vezes são pontuais. E ainda ressalta que é preocupante que não exista a preocupação de se construir uma realidade mais ampla, aprofundada e crítica da Educação Ambiental.

Na Educação Ambiental crítica, a tomada de posição de responsabilidade pelo mundo supõe a responsabilidade consigo próprio, com os outros e com o ambiente, sem dicotomizar e/ou hierarquizar essas dimensões da ação humana. Para estimular uma compreensão complexa, politizadora e transformadora dos problemas socioambientais, é preciso priorizar a compreensão multidimensional do problema ambiental, pois apenas o foco sobre uma ação de tipo corretiva produz um resultado reducionista e despolitizado, já que dilui a responsabilidade social sobre o problema. Para uma abordagem mais política, é preciso enfatizar uma visão interdisciplinar dessa questão que integra a crítica, o foco sobre a sua causa e a ação preventiva (GUIMARÃES, 2004).

Loureiro (2004a) afirma que é necessário construir um novo patamar societário e de existência integrada às demais espécies vivas e em comunhão com os seres humanos. Para tanto, é preciso superar as formas de expropriação que propiciam a dicotomia sociedade-natureza, que não vejam as relações sociais como negação das relações naturais ou ecológicas.

Assim, observou-se na fala dos entrevistados uma visão ingênua de que as responsabilidades ambientais são individuais e que as ajudas coletiva e da empresa Furnas já seriam suficientes. As pessoas "naturalizam" a falta do compromisso governamental na responsabilidade com tal questão. Estamos vivendo uma crise do pensamento crítico, em que há uma crise de poder e de análise crítica.

\section{Categoria 3 - Implicações ambientais da implantação da Usina Hidrelétrica de Batalha}

"A implantação da UHE de Batalha e suas implicações ambientais" consiste em uma categoria que busca compreender as principais modificações causadas pela implantação da UHE de Batalha na vida cotidiana dos moradores, bem como identificar na fala dos entrevistados o apontamento de impactos ambientais que fo- 
ram oriundos do empreendimento ou provenientes de costumes locais.

Entre as assertivas, destacam-se:

E1: A construção da usina matou uma boa área de vegetação. Igual, na minha propriedade mesmo, matou metade da vegetação. $E$ não foi reflorestado nenhum metro. Então, o desmatamento é um problema seríssimo. Outro problema é a queimada indiscriminada. O povo tem a mania de queimar... Agora a erosão já é uma questão natural, o terreno mesmo já causa erosão. Não é tanto pela agressão humana, mas é por causa do terreno mesmo.

E8: Eu tenho o poço e tenho a água do córrego. A água do meu poço nunca tinha secado. Mas, nesses dias mesmo, nós estamos no seco. Sem água nenhuma. É a primeira vez que acontece e, na minha opinião, é a usina que está chupando, que interferiu. Por que 'tá' represando lá. Além disso, eles desmataram demais [....] E9: Eu acho assim, se a implantação da usina é para poder o Brasil crescer, se é pra poder dar melhoria para as pessoas, eu acho que deve acontecer. Porque é muito importante. Mas, eu acho que teve pontos ruins também, até teve uma moça que foi picada por uma cobra. Como a área alagada foi muito grande e algumas árvores foram retiradas, amontoadas perto da casa dela, ela, pegando lenha, foi picada por uma cobra. Poderia ter acontecido sem ter essa inundação, mas eu penso que foi devido a essa inundação. Desalojou os bichos que estavam lá, e eles foram procurar outro lugar pra morar, que é perto da nossa casa. [...] Como outro problema, eu posso apontar a queimada. A maneira que a gente desfaz do lixo. Queimamos. A forma de matar o mato também, eu uso muito veneno. Eu sei que isso acaba com a terra. Eu sei que isso é errado, porque eu já comprovei lá.

E13: Quanto à erosão, tem problemas nas estradas, aqui dentro da minha área, inclusive, mesmo com Furnas tendo feito várias curvas de nível. Fizeram para conter a água, mas embaixo, onde não foi feito, a erosão está lá. E feia. E as estradas, basta chover bastante, que até o carro para buscar as crianças aqui fica difícil. Então, aqui tem um problema sério com a erosão. Sério mesmo.

E14: Nós tivemos perdas econômicas [...] para nós que vivíamos basicamente do leite. No Jambeiro, a produção era melhor do que aqui no São Cristóvão. Mas a gente teve vários problemas aqui e eu não sei se posso dizer que é relativamente ligado à mudança em si, ou se não. Mas a gente perdeu algumas cabeças de gado. E15: Ah, quanto à implantação da usina, a gente, a família, marido e filhos só pensava que ia ser ruim. Porque a gente ia sair do lugar [...] é [...] desestrutura a gente.

E17: Como impacto ambiental, seria a destruição da natureza, né? Porque a região nossa lá, no Jambeiro, a parte de vegetação era só na beira dos córregos mesmo, era pouquinha coisa e foi tudo para debaixo d'água.
De modo geral, os entrevistados identificaram os problemas ambientais, como: a queima do lixo, a queimada do pasto, o uso de agrotóxico, os processos erosivos, o desmatamento e a falta de água, além de citarem o fato de saírem de seu lugar de origem para serem remanejados para outro local, como um impacto negativo. Cassiano \& Echeverría (2014) ressaltam que as questões que abrangem a desapropriação de terras e a quebra dos laços afetivos nos espaços sociais devem ser elementos fundamentais para que os indivíduos possam tomar consciência do ambiente e dos problemas que existem nele, como um meio de possibilitar a condição de (des)cobrir as causas que favorecem a crise ambiental.

Ao serem questionados a respeito da implantação da UHE de Batalha e de seus consequentes impactos ambientais, os entrevistados apontaram a perda de vegetação em virtude da formação do reservatório e do alagamento, o deslocamento dos animais em decorrência da destruição de seu habitat natural e o aprofundamento do lençol freático, dificultando a obtenção de água por meio de poços em algumas propriedades.

Reconhecidamente, a queimada e o desmatamento são agravados pelas práticas locais de incineração de lixo e limpeza do terreno para fins agrícolas. Porém, os moradores locais, por falta de conhecimento e de condições financeiras, convivem com as dificuldades de abandonar essas atitudes impactantes, assim como ocorre com o uso de agrotóxicos.

Quanto aos processos erosivos, é notório que as condições naturais do solo e do terreno, em alguns locais dos assentamentos, já são propícias à formação de sulcos e ravinas. Porém, atitudes como o desmatamento excessivo, a ausência ou má execução das curvas de nível e de práticas de conservação do solo intensificam a recorrência de erosões em diversas propriedades e estradas de acessos.

Nesse sentido, percebe-se uma postura ingênua por parte dos moradores da região de que muitos problemas ambientais elencados poderiam ser evitados apenas com atitudes individuais relacionadas ao ambiente. A coleta de lixo na zona rural, por exemplo, é um encargo municipal. Ao assumirem tal postura, cometem o erro de transferir a responsabilidade governamental para os membros da coletividade, que, por sua vez, não conseguem solucionar sozinhos tal questão e, 
assim, permanecem impactando o ambiente sem reconhecer que uma atitude ecológica é mais que a soma de bons comportamentos.

Hungerford \& Volk (1990) definiram, com base em Tbilisi (1978), que os objetivos para a Educação Ambiental são: sensibilização, atitudes, habilidades e participação, e um cidadão ecologicamente correto que se preocupa, entende das questões ambientais e busca meios para resolvê-las ou ajudá-las. Porém, os autores citam que essa tarefa educativa, presente em Tbilisi, é, de certa forma, uma tarefa árdua, uma vez que o comportamento que esse sujeito deve apresentar vai além da prática educacional tradicional, pois além das habilidades e atitudes, deve-se ter uma presença ativa na sociedade. Há quem acredita que se ensinar um determinado assunto, o comportamento pode ser modificado. Porém, para que as questões ambientais possam ser integradas com o intuito de "mudança de comportamento", a instrução deve ser mais que do que apenas um conhecimento ou consciência do problema. As pessoas precisam desenvolver o sentido de "propriedade" e "empoderamento" para que possam, de fato, envolver-se em uma Educação Ambiental. Assim, um dos grandes desafios para os educadores é transformar esses objetivos de Tbilisi em uma realidade instrucional.

Ademais, como afirma Loureiro (2015), as atividades educativas devem ser voltadas para construção da igualdade e promoção das diversidades, para que possam ser eliminados os processos de dominação e expropriação. Assim, o conhecimento crítico leva o pensamento a ser voltado para a transformação social.

\section{Categoria 4 - A interpretação da população local das ações promovidas pela empresa Furnas vinculadas à Usina Hidrelétrica de Batalha}

A categoria "A interpretação da população local das ações promovidas pela empresa Furnas vinculadas à UHE de Batalha" identifica as opiniões da população local quanto às ações promovidas pela Furnas durante todo o processo de implantação da UHE de Batalha. Entre as falas dos entrevistados, apontam-se:

E1: Com o enchimento da barragem, a água lá em casa aumentou. Na água abaixar deu grota, aí minhas vacas andaram caindo. Caíram três, eu dei conta de salvar uma, mas perdi duas vacas paridas, né? E eu reclamei com Furnas e nunca tive resposta, e isso já faz quatro meses. Só que eles têm que fechar uma APP, que é de obrigação do consórcio, e lá em casa não fecharam a APP. Fecharam em alguns locais, mas têm outros que não. Hoje, só em gado, perdi mais de $\mathrm{R} \$$ mil.

E11: [...] eles falaram que iam indenizar a gente. Antes de sair do lote, eles pagaram a indenização para o meu pai. Eles fizeram tudo direitinho. Explicaram para nós, perguntaram se nós aceitávamos. Aí nós aceitamos. [...] como eu e meu marido morávamos no fundo do lote do meu pai, eles falaram que iam indenizar nós também; 'pra' falar verdade, eles indenizaram, pagaram [...] porque nós morávamos no rancho, no fundo. Eles pagaram para a gente sair de lá, e deu outro lote para nós.

E13: Furnas, através da EMATER, traz para a gente alguns cursos que explicaram muita coisa boa. Mas, muitos atingidos não têm o interesse de participar. Todo curso bancado pelo governo tem que ter pelo menos 12 participantes. Aí, muitas vezes, os atingidos não dão esse número de pessoas e são convidados outros moradores do assentamento. [...] porque os atingidos não participam? Eu acho que é por falta de interesse.

E14: Depois que a gente estava no São Cristóvão, a gente exigiu o reservatório de água maior por causa do gado. Aí o pessoal de Furnas disse que não, que eles estavam olhando só o humano, mas quando saímos do Jambeiro já tinha vacas, a gente já tinha muitos animais, então [...] como se as vacas não bebessem água. Por isso a gente acabou perdendo alguns animais.

E15: A única coisa que eu lembro que não ficou claro foi o negócio das casas. Quando foi construir as casas, disseram que iam ter cerâmica, que as mulheres iam vir escolher as cores da cerâmica [...] e isso não foi feito. [...] E a minha casa lá do Jambeiro era de 4 quartos, era grande e eu não entendo porque essa daqui tem que ser tão pequena.

E16: É o que aconteceu. Ficou uns dois anos esperando para mudar. Eles construíram primeiro para o povo que ficou no Jambeiro e nós, do São Cristóvão, tivemos que esperar com a vida parada por quase dois anos. [...] Se hoje me acontecesse uma coisa dessas da gente ser atingido, a experiência da gente era outra. Passou batido muita coisa.

E17: A gente não podia plantar nada, não podia formar pasto nem consertar a cerca lá no Jambeiro, porque Furnas falou que a gente ia mudar. Isso foi por três anos praticamente. Três anos nós ficamos parados lá. A gente tinha certeza que a gente não podia ficar lá e não tinha nada pra provar como que a gente ia mudar. Aí o que a Furnas fez? Ela fez as estruturas do assentamento ao redor do lago, atendeu às demandas do pessoal do Jambeiro, e quem ia ser remanejado para São Cristóvão, como não atrapalharia as obras dele, eles deixaram lá, foi ficando [...]. 
E18: Para mim, foi negócio ruim, porque morreu muita criação minha quando veio para o São Cristóvão. Eu tinha silagem pronta lá no Jambeiro; eles trouxeram eu pra cá, na frente, e deixaram o silo lá. As vacas do vizinho bagunçaram tudo, vaca minha morreu de seca aqui, foi trazendo os "trem"1 picadinho de caminhonete, tudo veio perdendo, vaca intoxicando com comida, o leite despencou tudo, bagunçou tudo [...] Só prejuízo. Nada foi ressarcido. Eles tinham tratado de dar de comer para as vacas nossas, porque nós viemos fora de hora. Nós já viemos num período que já tinha acabado as chuvas, tinha tratado de dar o trado pra nós e acabou que eles liberaram o dinheiro de aplicação do trado na terra depois de a chuva já ter acabado. Eu perdi 11 cabeças de criação até hoje não me deu nenhum centavo e era uma coisa que eles tinham que arcar. Eles trataram que iam dar a comida do gado para nós e não deram.

Entre as falas dos entrevistados, pode-se destacar que os moradores, tanto do PA Jambeiro quanto do PA São Cristóvão, identificam ações promovidas pela Furnas durante a implantação da UHE de Batalha, em especial as relacionadas com as questões financeiras, indenizações, construção de novas casas, apoio técnico agrícola pela Empresa de Assistência Técnica e Extensão Rural (Emater) e cursos promovidas pela equipe de Educação Ambiental de Furnas.

No entanto, percebem-se opiniões divergentes entre os moradores atingidos e indenizados que permane- cem no PA Jambeiro, que denominamos de atingidos 1 e removidos 1 , e aqueles que foram transferidos para o PA São Cristóvão (removidos 2). Os moradores (removidos 1) que, apesar de terem se mudado para lotes vizinhos, permaneceram no PA Jambeiro, convivendo com a mesma comunidade, ressaltam a importância disso e não explicitam tantas perdas financeiras nem descontentamento com a assistência promovida pela Furnas. Apenas apontaram como obrigação de Furnas ainda não realizada o fechamento de todas as Áreas de Preservação Permanente (APPs).

Quanto àqueles que foram remanejados para o PA São Cristóvão (removidos 2), uma área geograficamente distante e com características distintas de sua área de origem, demonstram clara insatisfação com a mudança. Esse grupo de moradores expressa seu descontentamento citando as perdas financeiras significativas e a inobservância da Furnas quanto à necessidade de maior atenção e comunicação com eles durante o longo período de espera para sua efetiva mudança. É possível reconhecer que parte dessa insatisfação explicitada pelos entrevistados que passaram pelo processo de remoção pode ser proveniente da comunicação falha entre as reais ações propostas pela Furnas e a comunidade. De modo geral, esses moradores ficaram deslumbrados com promessas que podem não ter partido da Furnas, criando expectativas não atendidas.

\section{CONSIDERAÇÕES FINAIS}

Esta pesquisa foi desenvolvida com o objetivo central de analisar a concepção ambiental dos sujeitos sociais envolvidos na implantação da UHE Batalha, situada nos municípios de Cristalina (GO) e Paracatu (MG), ponderando sobre o conhecimento, os acordos e os desacordos sobre o assunto, e identificar possibilidades de intervenção e reconhecimentos de responsabilidades individuais e coletivas diante dos impactos ambientais.

A realização de entrevistas semiestruturadas com 18 moradores da AID da UHE Batalha, PA Jambeiro e PA São Cristóvão, mostrou que eles possuem histórias distintas, uma vez que alguns acompanharam a implantação da usina e outros não, e isso intervém na forma como percebem as mudanças ocasionadas por ela.
Durante as entrevistas ficou clara a predominância de diferentes visões da natureza, que os leva a não se sentirem parte integrante da mesma e, consequentemente, ao sentimento de não pertencimento ao ambiente. Essa lacuna existente entre homem e natureza é resultado do Antropocentrismo, que coloca o homem como o centro de tudo, no qual a natureza existe apenas como um objeto em função dos humanos. A objetivação e a fragmentação da natureza são resultados da busca da autonomia da razão e isso pode ser considerado um dos elementos responsáveis pela devastação ambiental, devido à separação entre sujeito e objeto e natureza e cultura.

Os problemas ambientais na região da UHE Batalha identificados pelos entrevistados estão, em sua maioria, re-

1Trem: em Goiás, há o costume de utilizar a palavra "trem" para se referir a coisas. Na frase "foi trazendo os 'trem' [...]" significa: foi trazendo as coisas. A expressão "trem bão" significa coisa boa. 
lacionados à instalação da Usina e também citam alguns vinculados às suas práticas antrópicas cotidianas, como o lixo, as queimadas, o uso de agrotóxicos, entre outros. Existe a recorrência da importância das atitudes individuais perante o ambiente e da identificação da necessidade da prática de todos para que haja consolidação destas ações. Com essa visão ingênua, trazem para si e para a comunidade local a responsabilidade de resolver, compensar ou corrigir grande parte dos problemas, sem reconhecer que muitos desses problemas dependem de outras esferas sociais e governamentais para sua real resolução. Esse é o resultado da crise do pensamento crítico que está instaurado, no qual existe uma crise do padrão de poder e ao mesmo tempo do saber.

Carvalho (2011) cita que o ser humano tem o direito de agir conforme sua consciência, porém respeitando os valores da sociedade, que possui normas impostas pela coletividade, sendo que a responsabilidade civil parte da quebra dos limites impostos à liberdade. A responsabilidade civil apresenta três esferas principais: a conduta humana, o dano e o nexo de causalidade, e, como elemento acidental, a culpa. Assim, as mudanças que devem ocorrer para que possam ser reparados os danos podem ser entendidas como mudanças de paradigma de responsabilidade civil.

Em relação ao entendimento das ações promovidas pela Furnas durante a implantação da UHE Batalha, este se configura de forma diferente de acordo com o grupo de moradores, que foi ou não removido para outro assentamento. Existem dois grandes grupos, um que permaneceu no PA Jambeiro após a implantação da usina e outro que foi remanejado para o PA São Cristóvão. Ambos, por falta de comunicação e clareza quanto às ações da Furnas para com eles, observam de forma positiva a posi- ção do outro grupo e de forma negativa a sua própria condição. Por não conhecerem, de fato, a realidade uns dos outros, alguns desses moradores se sentem injustiçados ou desvalorizados perante os outros.

De forma generalizada, as queixas apresentadas pelos entrevistados referem-se às suas perdas financeiras e sociais. Os elogios são direcionados aos benefícios recebidos, como a construção de casas novas e as assistências da equipe técnica da EMATER. Compreendem a implantação da usina como uma necessidade do país pela demanda de energia, e são capazes de identificar pontos positivos (via de regra, relacionados às benesses adquiridas no processo) e negativos (correspondentes às perdas sociais, emocionais e financeiras) desse empreendimento. Os problemas ambientais existentes na região são colocados como fatos a serem trabalhados individualmente, e que as pessoas acreditam que se houvesse mais apoio e colaboração coletiva, seria possível construir um espaço ecologicamente sustentável, não conseguindo compreender que as questões socioambientais estão inseridas em uma trama social mais complexa do que a das realidades locais.

Diante do exposto, verifica-se a necessidade de promover maior participação das pessoas na tomada de decisões, bem como de criar meios de comunicação mais formais que possam, de fato, sanar as dúvidas em relação às questões e aos impactos socioambientais na região decorrentes da implantação desse tipo de empreendimento, especialmente para as pessoas que serão diretamente atingidas, para que possam expor suas opiniões e também ser informados adequadamente sobre os benefícios e as consequências no ambiente e na população do entorno. É necessário incluir as pessoas no processo e que as informações não sejam omitidas.

\section{AGRADECIMENTOS}

As autoras agradecem à Agência Nacional de Energia Elétrica (ANEEL) e à Eletrobras Furnas pelo apoio financeiro, iniciativa e motivação para a realização da pesquisa, que fez parte do Projeto ANEEL nº 0394-1014-2010 -
Monitoramento e Estudo de Técnicas Alternativas na Estabilização de Processos Erosivos em Reservatórios de UHEs, desenvolvido em parceria entre Eletrobras Furnas e Funape/UFG.

\section{REFERÊNCIAS}

BARDIN, L. Análise de conteúdo. São Paulo: Edições 70, 2011.

BOGDAN, R.; BIKLEN, S. K. Características da investigação qualitativa. In: BOGDAN, R.; BIKLEN, S. K. Investigação Qualitativa em Educação: uma introdução à teoria e aos métodos. Porto: Porto, 1994. 
BRASIL. Constituição da República Federativa do Brasil. Brasília: Senado Federal: Centro Gráfico, 1988. 292 p. Disponível em: <http://www.planalto.gov.br/ccivil_03/constituicao/constituicao.htm> Acesso em: 30 out. 2015.

. Lei n. ${ }^{0}$ 4.504: Estatuto da Terra. Câmara dos Deputados: Centro de Documentação e Informação, 1964.

CARVALHO, D. P. Thomas Kuhn e o novo paradigma da responsabilidade civil: em busca da reparação da perda de uma chance. Jus Navigandi, Teresina, ano 16, n. 2826, 28 mar. 2011. Disponível em: <http://jus.com.br/artigos/18783>. Acesso em: 11 maio 2015.

CARVALHO, I. C. M. Educação ambiental: a formação do sujeito ecológico. 2. ed. São Paulo: Cortez, 2006.

CASSIANO, K. F. D.; ECHEVERRÍA, A. R. Abordagem ambiental em livros didáticos de Química: Princípios da Carta de Belgrado. Química Nova Escola, São Paulo, v. 36, n. 3, p. 220-230, 2014.

GRÜN, M. O conceito de holismo em ética ambiental e educação ambiental, p. 45-50. In: Educação ambiental: pesquisa e desafios, Michèle Sato \& Isabel Carvalho (orgs.). Porto Alegre: Artmed, 2005, Disponível em: <http://www.institutoaf. org.br/Sato_artmed[1].pdf>

GUIMARÃES, M. A dimensão ambiental na educação. 7. ed. Campinas: Papirus, 2005.

. A formação de educadores ambientais. Campinas: Papirus, 2004a.

. Armadilha paradigmática na educação ambiental. In: LOUREIRO, C. F. B.; LAYRARGUES, P. P.; CASTRO, R. S. de (Orgs.). Pensamento complexo, dialética e educação ambiental. São Paulo: Cortez, 2011.

. Educação Ambiental Crítica: Identidades da Educação Ambiental Brasileira. Brasília: Ministério do Meio Ambiente, 2004b.

HUNGERFORD, H. R.; VOLK, T. L. Changing Learner Behavior through Environmental Education. The Journal of Environmental Education, Carbondale, 1990.

INSTITUTO BRASILEIRO DE ANÁLISES SOCIAIS E ECONÔMICAS (IBASE); FURNAS CENTRAIS ELÉTRICAS S.A. (FURNAS). Diagnóstico social do PA Jambeiro - AHE Batalha Município de Paracatu - MG. 2010. Disponível em: <https://pt.scribd. com/document/99725186/Diagnostico-social-de-Jamberio>. Acesso em: 10 fev. 2015.

LOPES, S. F.; VIEIRA, R. M.; MOREIRA, A. WEBQDA na análise qualitativa de interações no contexto de uma oficina de formação de professores. Indagatio Didactica, v. 5, n. 2, 2013.

LOUREIRO, C. F. B. Educação ambiental e epistemologia crítica. Revista Eletrônica do Mestrado em Educação Ambiental, v. 32, n. 2, p. 159-176, 2015.

. Educação Ambiental Transformador. In: LAYRARGUES, P. P. (Coord.). Identidades da Educação Ambiental Brasileira. Brasília: Ministério do Meio Ambiente/Diretoria de Educação Ambiental, 2004.

. Sustentabilidade e educação: um olhar da ecologia política. São Paulo: Cortez, 2012.

PARDO, J. R. Las riquezas que habitan en la tierra non son recursos naturales sino bienes comunes. ¿Por qué bienes comunes? Observatório Latinomaericano de Conflictos Ambientales, 2008. Disponível em: <http://www.olca.cl/oca/ mineras/mineras009.htm>. Acesso em: 23 abril 2015.

PORTO-GONÇALVES, C.W. Lucha por la Tierra. Ruptura metabólica y reapropiación social de la natureza. Revista Latinoamericana, v. 15, n. 45, p. 291-316, 2016.

PORTO-GONÇALVES, C.W.; LEFF, E. Political Ecology in Latin America: the Social Re-Appropriation of Nature, the Reinvention of Territories and the Construction of an Environmental Rationality. Desenvolvimento e Meio Ambiente, v. 35, p. 65-88, 2015. 
PORTO-GONÇALVES,C. W. Os (des)caminhos do meio ambiente. São Paulo: Contexto, 2004.

REIGOTA, M. O que é Educação Ambiental. São Paulo: Brasiliense, 2009.

RIOS, F. P. Capacidade de suporte de cursos d'água urbanos sob a perspectiva técnica e epistemológica da engenharia. 114 f. Tese (Doutorado em Ciências Ambientais) - Programa de Pós-Graduação em Ciências Ambientais, Universidade Federal de Goiás, Goiânia, 2015.

SAUVÉ, L. Educação ambiental e desenvolvimento sustentável: uma análise complexa. Revista de Educação Pública, v. 6, n. 10, p. 72-102, 1997. ago. 2005.

. Educação Ambiental: possibilidades e limitações. Educação e Pesquisa, São Paulo, v. 31, n. 2, p. 317-322, maio/

SILVA, L. F. Educação Ambiental crítica: entre ecoar e recriar. 197 p. Tese (Doutorado em Educação) - Programa de PósGraduação em Educação, Universidade de São Paulo, São Paulo, 2009. 